\title{
Determination of Geotechnical Properties and Stability of Expansive Soil using Fly Ash
}

\author{
Farhan KHAN ${ }^{1, *}$, Bhumika DAS ${ }^{2}$ and Nomesh DEWANGAN ${ }^{3}$ \\ ${ }^{I}$ Department of Civil Engineering, Rungta College of Engineering and Technology, Bhilai, \\ Chhattisgarh 490024, India \\ ${ }^{2}$ Mats University, Raipur, Chhattisgarh 492001, India \\ ${ }^{3} P G$ Scholar, CSVTU, Bhilai, Chhattisgarh 491107, India
}

('Corresponding author's e-mail: farhan_1991@rediffmail.com)

Received: 9 March 2021, Revised: 29 April 2021, Accepted: 5 May 2021

\begin{abstract}
This study was conducted to have a detailed analysis of the geotechnical properties of expansive soil and fly ash from Sipat thermal power plant. It reported the findings of laboratory studies on certain common physical and geotechnical properties. The chemical properties and morphology of the black cotton soil (BCS) and fly ash is also determined using scanning electron microscopy and X-ray diffraction test. The geotechnical test includes determining specific gravity, particle size distribution, moisture content, standard proctor test, free swell index, and Atterberg's limit. The different compositions of expansive soil with fly ash, yellow soil, moorum, and sand are studied. BCS was evaluated with fly ash, fly ash and sand, BCS with yellow soil, and moorum and fly ash. The study also analyzed the details and results of different tests conducted on soil samples. The results showed that strength and fly ash are inversely proportional; as fly ash increases, strength decreases, and vice versa. Fly ash was added from 20 to $80 \%$ by replacing expansive soil by weight. The results indicated that expansive soil can be stabilized by the addition of fly ash to a limit of 10 to $20 \%$.
\end{abstract}

Keywords: Expansive soil, SEM, XRD, Fly ash, Mineralogy

\section{Introduction}

\section{Expansive soil}

Expansive soils are identified by significant volume changes with changes in moisture content, causing major structural failure and collapse, especially for light structures and pavements constructed on them. Different forms of soils are used in structural engineering structures; however, certain soil formations in their normal states are ideal for building purposes, and others, such as problematic soils, are unsuitable without treatment. Expansive soil is also known as problematic soil [1]. Typically, they are distinguished by a high plasticity, swelling potential and shrinkage potential, and low permeability and strength in wet areas. Due to the above properties, they are volumetrically unstable [2]. For improvement purposes, expansive soil is replaced, or the properties are changed by adding additional material to the soil [3]. As the moisture content increases, volumetric changes happen to expansive soil; this can be minimized by adding lime, fly ash, bitumen, cement, and other chemicals [4,5]. Expansive soil is considered one of the worst soils for civil construction, as engineers have to pay extra attention during the construction of structures using it. Black cotton soil is composed of fine-grained soil or decomposed rocks that show huge volume changes when subjected to variability in moisture content. Expansive soil shows swell-shrink behavior near the ground surface due to the land covered by expansive soil [6,7]. These soils occupy approximately $8.9 \times 10 \mathrm{~km}^{2}$ in India; approximately one-fifth of their surface area covers the states of Maharashtra, Gujarat, Uttar Pradesh, Madhya Pradesh, Rajasthan, Andhra Pradesh, 
http://wjst.wu.ac.th

and Tamil Nadu [8,9]. Black cotton soil is composed of fine-grained soil or decomposed rocks that show huge volume change when subjected to variability in moisture content; expansive soil shows swell shrink behaviour near the ground surface due to direct contact with variation in seasons and environment $[10,11]$. Under drying or warm settings, soil moisture content reduces, and overall volume shrinks. The subsequent incremental development of desiccation cracks creates detrimental consequences on expansive soil's mechanical and hydraulic behaviors [12]. Expansive soil consists of hydrophilic minerals, such as Illite and montmorillonite, and is a generally troublesome expansive soil conceived in natural geological processes. Expansive soil is distinguished by shrinkage and expansion[13]. In India, $20 \%$ of the land is covered by expansive soil [6].

\section{Fly ash}

The material, which is the byproduct of the thermal power station and coal industries, was collected from fly ash gases. This is composed of very fine silt particles which are dumped into landfills. The production of fly ash is very high as compared to its consumption in India [14]. Fly ash is a good water absorbent; it can be used to increase the strength of the soil. Fly ash contains macro and micro nutrients that can support agriculture growth; $40 \%$ of fly ash is suitable for agriculture use [15]. Due to urbanization, the demand for power supply increases, resulting in increasing numbers of power plants, which after combustion of coal generates fly ash as a residue [16]. The disposal of ash with safety towards the environment is also important. The utilization of fly ash alternative should be determined. The bulk use of fly ash can be done in geotechnical fields for embankments, retaining walls, soil replacement, etc. $[17,18]$. Fly ash is now used for making bricks, and it is added in different proportions to soil to improve its strength. This results in a fast hydration mechanism and a concurrent cation exchange, as lime and fly ash are added into a soil that flocculates the soil into larger lumps [2]. Murmu et al. studied the use of fly ash for the stabilization of expansive soil [19].

The objective of the research is to determine the effect of fly ash content on expansive soil. The standard proctor test is used, and specific gravity is determined. The maximum dry density and optimum moisture content of the different proportions of soil were analyzed. This analysis helps in selecting good soil-ash composition for field work. The results obtained from this research showed how expansive soil behaves after adding fly ash. XRD and SEM analysis were carried out to determine the chemicals present in the samples and their sizes. Particle size distribution analysis was performed to determine the sizes of particles present in the samples [20]. Nalbantoğlu studied particle size increases with increase in curing time [21].

\section{Materials and methods}

In this study, black cotton soil (BCS), yellow soil, and moorum were used for testing purposes, and fly ash (FA) was collected from the Sipat National Thermal Power Plant of Chhattisgarh. Different proportions of BCS, yellow soil, and moorum were taken and mixed with fly ash to determine the standard proctor test result, specific gravity, and particle size distribution. To stabilize BCS economically, only 10 to $15 \%$ of class F fly ash was required [22,23]. The different samples were tested to determine index properties. Similarly, X-ray diffraction analysis (XRD) and scanning electron microscopy (SEM) of BCS and fly ash was done to determine the mineral composition and particle study, as shown in Figure 1. The different samples were then collected in different proportions to determine stable compositions. The soil collected was dried and crushed into the appropriate sizes and checked according to IS:2720 for its physical characteristics, such as gradation, compaction, and strength. 

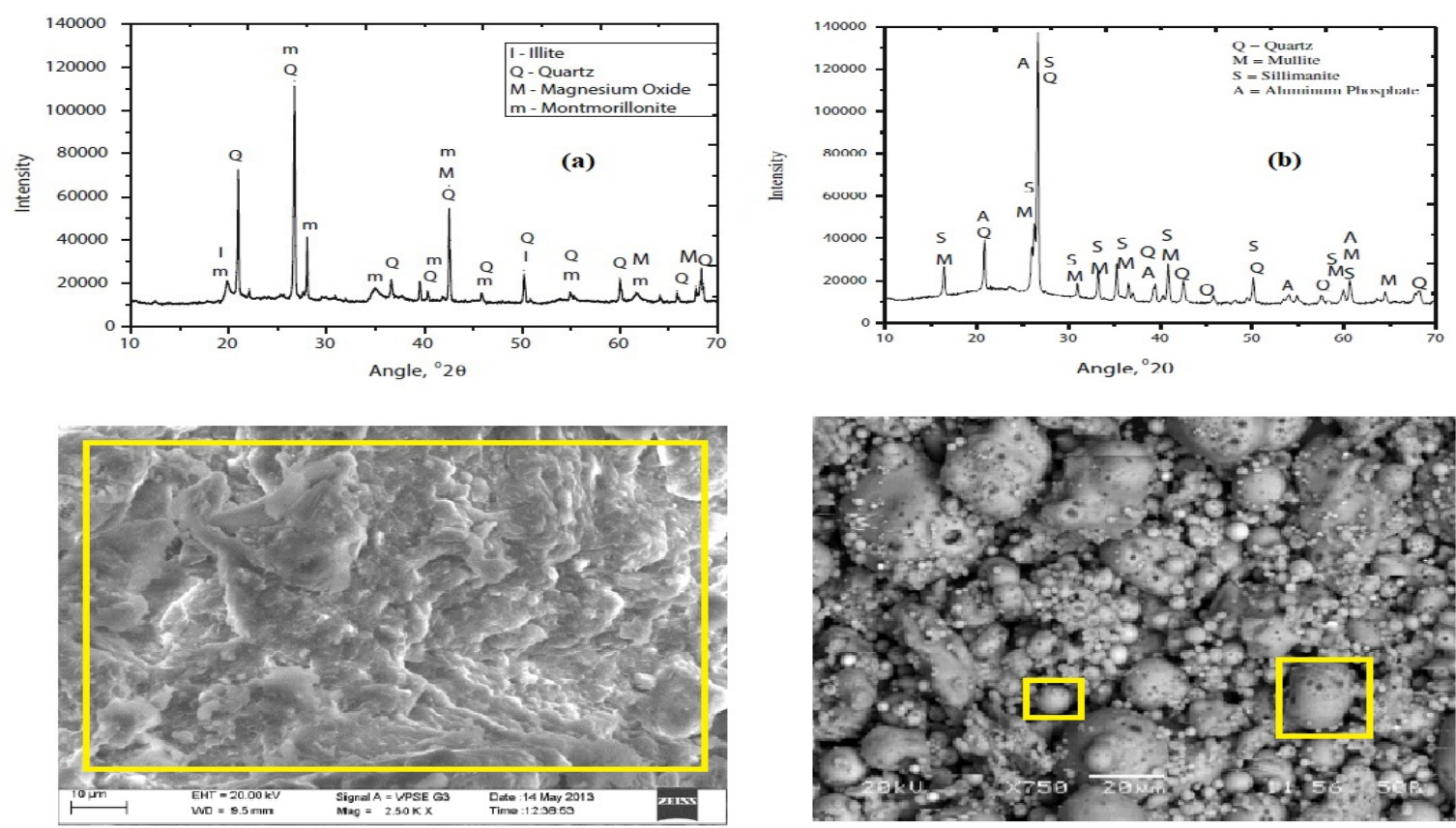

(c)

(d)

Figure 1 Figure 1(a, b) shows the XRD for BCS and fly ash, and (c, d) shows the SEM of BCS and fly ash, respectively.

Both BCS and FA chemical compositions were calculated using the X-ray diffraction analysis (XRD) method. The BCS and FA findings of the XRD study are presented in Table 1. Table 1 reveals that $\mathrm{A} 12 \mathrm{O} 3, \mathrm{SiO} 2$, and $\mathrm{Fe} 2 \mathrm{O} 3$ are the main phases present in the BCS and FA. In addition, based on ASTM C618 (2010) classification, the FA is categorized as class F fly ash, as the amount of Al2O3 $(22.85 \%), \mathrm{SiO} 2(59.92 \%)$ and $\mathrm{Fe} 2 \mathrm{O} 3(5.65 \%)$ is greater than $70 \%$. The soil index characteristics are calculated in accordance with IS 2710-part V (1985) and are shown in Table 2.

Table 1 Chemical composition of BCS and fly ash.

\begin{tabular}{ccc}
\hline Composition (\%) & Black cotton soil (BCS) & Fly ash \\
\hline $\mathrm{SiO}_{2}$ & 52.12 & 59.92 \\
$\mathrm{Al}_{2} \mathrm{O}_{3}$ & 14.29 & 22.85 \\
$\mathrm{Fe}_{2} \mathrm{O}_{3}$ & 9.89 & 5.65 \\
$\mathrm{MgO}$ & 3.76 & 0.76 \\
$\mathrm{CaO}$ & 3.15 & 0.89 \\
$\mathrm{~K}_{2} \mathrm{O}$ & 0.89 & 1.32 \\
$\mathrm{Na}_{2} \mathrm{O}$ & 0.67 & 0.11 \\
\hline
\end{tabular}


Table 2 Geotechnical properties of soil.

\begin{tabular}{ccccc}
\hline Properties & Expansive soil & Yellow soil & Moorum & Fly Ash \\
\hline Color & Brownish black & yellowish & Brownish red & Grey \\
Specific gravity & 2.91 & 3.52 & 2.54 & 1.79 \\
Free swell index (FSI) (\%) & 65 & 10.4 & 8.7 & - \\
Liquid limit (LL) (\%) & 57 & 41.58 & 43 & - \\
Plastic limit (PL) (\%) & 29 & 22.23 & 21.40 & - \\
Plasticity index (PI) (\%) & 28 & 19.35 & 21.6 & - \\
Soil classification (as per IS: $1498-1970)$ & $\mathrm{CH}$ & $\mathrm{CL}$ & - & - \\
Optimum moisture content (OMC) $(\%)$ & 22.91 & 19.23 & 12 & - \\
Maximum dry density (MDD) $(\%)$ & 1.60 & 1.74 & 2.16 & - \\
Maximum dry unit weight (kN/m $\left.\mathrm{m}^{3}\right)$ & 17.94 & 15.53 & 16.67 & - \\
\hline
\end{tabular}

\section{Methods}

To determine the different properties of soil, the IS code was referred to, and with accordance to the code book, the different tests are performed. The standard proctor test was performed following IS: 2720 (Part 7) - 1980, liquid and plastic limit test - IS 2720 (Part 5) - 1985, free swell index test - IS 2720 (Part 40) - 1977, specific gravity - IS 2720 (Part 3/Sec 1) - 1980, MDD and OMC - IS 2720 (Part 7) - 1980, water content-IS 2720 (Part 2) - 1973.

The samples for different tests were collected from different locations, and were preserved from atmospheric moisture. The samples were used for different analyses to obtain the analytical values and results in the Laboratory of the National institute of Technology, Raipur.

\section{Results and discussion}

\section{Particle size distribution}

For proper understanding of particle sizes in soil samples, particle size analysis should be performed. From particle size distribution (PSD), particles of different sizes present in a soil mass can be easily determined, and their distribution with accordance to size can also be found. The studies suggest that soil particle size increases with curing time $(2 \mathrm{~m}-0.075 \mathrm{~mm})$. The different sizes of particles are plotted in Figure 2, and the data of analysis is given in Table 3. The particle sizes were finer than 10, 30, and $60 \%$ were determined as D10 $=0.30 \mathrm{~mm}$, D30 $=0.40 \mathrm{~mm}$, and D60 $=0.55 \mathrm{~mm}$. The coefficient of curvature $\mathrm{Cc}=1.83$ and the coefficient of uniformity $\mathrm{Cu}=0.97$.

$\mathrm{Cu}=\mathrm{D} 60 / \mathrm{D} 10=0.55 / 0.30=0.97$

$\mathrm{CC}=\mathrm{D} 302 / \mathrm{D} 60 \mathrm{D} 10=(0.30) 2 / 0.55 \times 0.30=1.83$

As we know, when $\mathrm{Cu}$ is less than 4 , it is classified as poorly graded or uniformly graded soil. Uniformly graded soil has identical particles, with $\mathrm{Cu}$ value approximately equal to 1 . Here, it is less than 1, i.e., $=0.97$.

For the soil to be well-graded, the value of Cc must range between 1 and 3. Here, it is between 1 and 3, i.e., $=1.83$. 
http://wjst.wu.ac.th

Table 3 Particle size distribution (PSD).

\begin{tabular}{cc}
\hline Particle diameter $(\mathbf{m m})$ & Percentage finer (\%) \\
\hline 2.36 & 99.85 \\
1.18 & 86.295 \\
0.600 & 62.790 \\
0.425 & 31.56 \\
0.300 & 10.00 \\
0.250 & 5.810 \\
0.150 & 0.190 \\
0.088 & 0.050 \\
0.075 & 0.012 \\
\hline
\end{tabular}

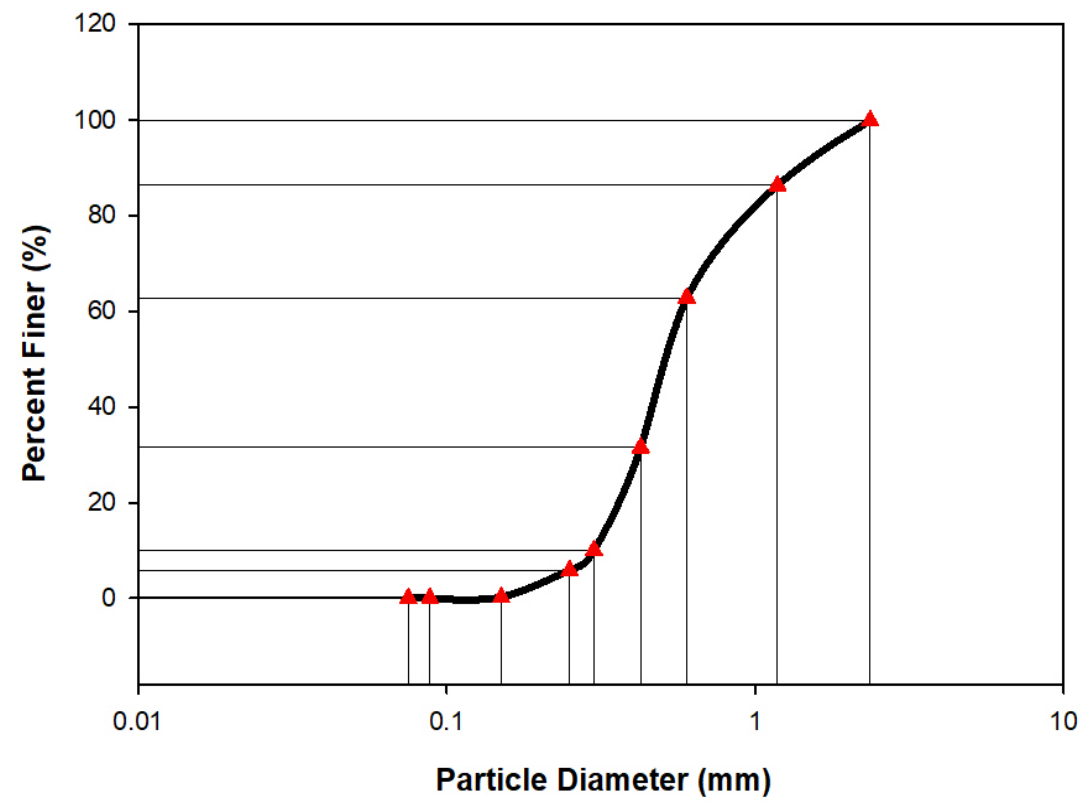

Figure 2 Particle size distribution curve of BCS.

\section{Standard proctor test}

To determine the soil density and moisture content, the standard proctor was performed on different compositions of soil. The first composition is of different percentages of fly ash with percentage of sand. In Figure 3, we can see how the density changes; after addition of fly ash, the MDD obtained for the same was $1.9 \mathrm{gm} / \mathrm{cc}$ and the value of OMC was $27 \%$. Detailed values are given in Table 4. From the study, it is clear that, on increasing the percent of fly ash, MDD decreases with an increase in OMC. Secondly, with values for BCS and fly ash composition in various percentages, the MDD decreases with 
http://wjst.wu.ac.th

an increase in moisture content. The value for MDD was $1.60 \mathrm{gm} / \mathrm{cc}$, which decreases to $1.28 \mathrm{gm} / \mathrm{cc}$, and OMC remains mixed from 22.91 to $21.21 \%$. Values are shown in Table $\mathbf{5}$ and in Figure 4. The third composition, which was tested, consists of different proportions of BCS, FA, YS, and M, given in Table 6. From the analysis of the above soil composition, it is confirmed that the value of MDD decreases from 1.65 to $1.58 \mathrm{gm} / \mathrm{cc}$ for BCS as we add fly ash, and OMC increases from 20.51 to $28.87 \%$ with increase in fly ash content, shown in Figure 5. The weight and volume of mold used is 1970 gms and $1005 \mathrm{cc}$, respectively.

For sand and FA, $20 \% \mathrm{FA}$ and $80 \%$ sand is suitable, as shown in the results; similarly, for BCS and FA, $40 \% \mathrm{FA}$ and $60 \mathrm{BCS}$ can be used as they give high MDD and low OMC.

Table 4 Standard proctor test results for fly ash and sand.

\begin{tabular}{cccc}
\hline \% of fly ash & \% of sand & OMC & MDD \\
\hline 0 & 100 & 6.67 & 1.60 \\
20 & 80 & 9.30 & 1.88 \\
40 & 60 & 6.67 & 1.81 \\
60 & 40 & 10.81 & 1.55 \\
80 & 20 & 26.47 & 1.26 \\
\hline
\end{tabular}

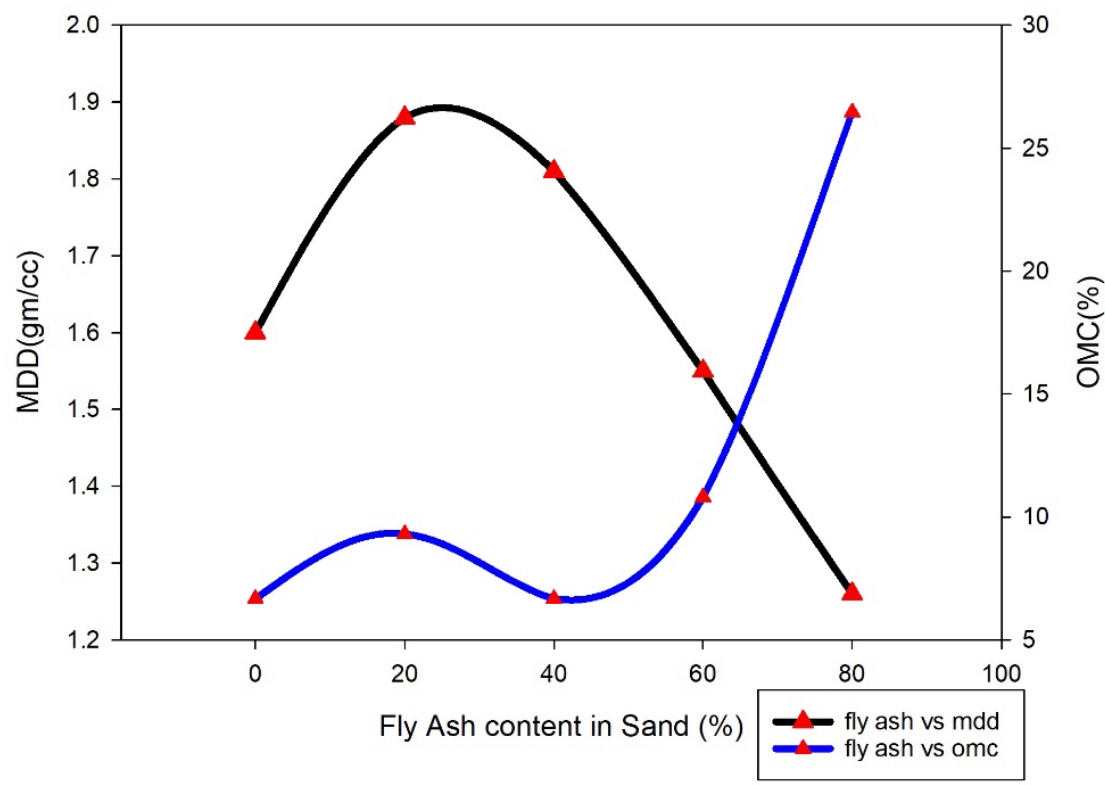

Figure 3 FA content in sand vs. MDD and OMC. 
Table 5 MDD and OMC for BCS and fly ash soil.

\begin{tabular}{cccc}
\hline$\%$ of fly ash & \% of BCS & OMC (\%) & MDD (gm/cc) \\
\hline 0 & 100 & 22.91 & 1.60 \\
20 & 80 & 20 & 1.56 \\
40 & 60 & 15.56 & 1.62 \\
50 & 50 & 22.5 & 1.58 \\
60 & 40 & 17.85 & 1.57 \\
70 & 30 & 25.45 & 1.42 \\
80 & 20 & 22.5 & 1.34 \\
100 & 0 & 21.21 & 1.28 \\
\hline
\end{tabular}

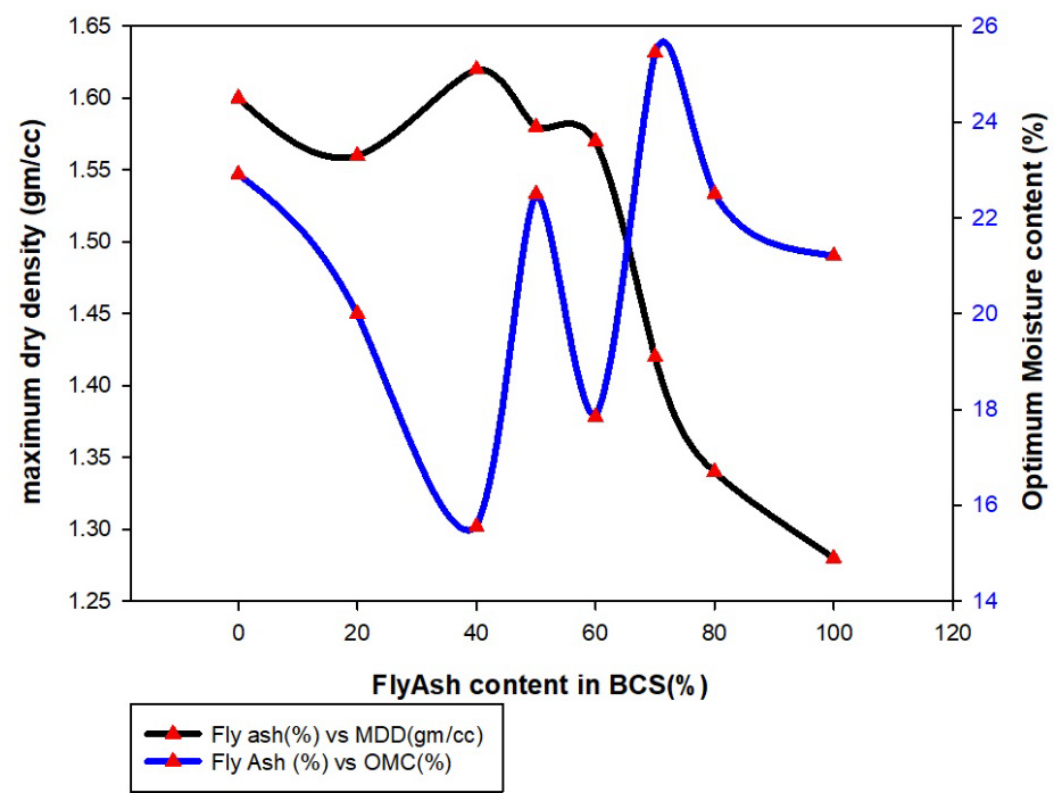

Figure 4 Fly ash content in BCS vs. MDD and OMC.

Table 6 OMC and MDD for different soil compositions.

\begin{tabular}{cccccc}
\hline \% of BCS & \% of yellow & \% of moorum & \% of fly ash & OMC (\%) & MDD (gm/cc) \\
\hline 50 & 10 & 10 & 30 & 20.51 & 1.65 \\
40 & 10 & 10 & 40 & 27.02 & 1.58 \\
30 & 10 & 10 & 50 & 28.87 & 1.58 \\
\hline
\end{tabular}




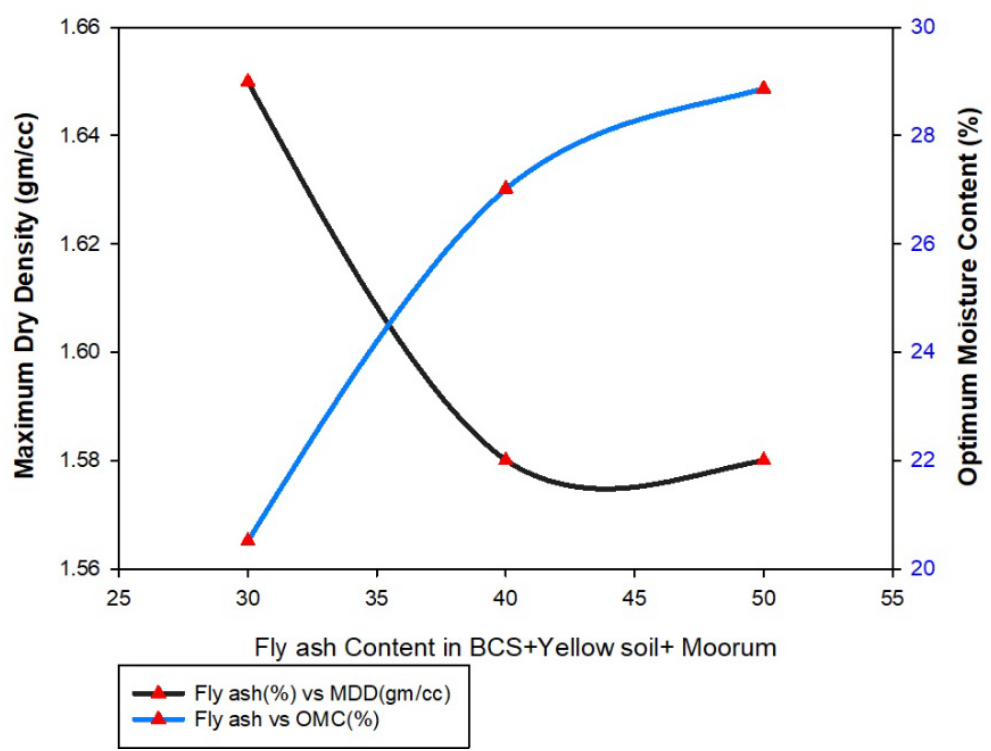

Figure $5 \mathrm{FA}+\mathrm{YS}+\mathrm{M}+\mathrm{BCS}$ vs. MDD \& OMC.

\section{X-ray diffraction analysis (XRD) and scattering electron microstructure (SEM)}

The chemical composition and minerology of fly ash and expansive soil was analyzed using XRD. The minerals found in the analysis are Illite, Quartz, Montmorillonite, and Magnesium Oxide in excess, shown in Table 1 and Figure 1. The basic mineral group found in this type of soil was studied by and tabulated in Table 1. The dominant mineral present in fly ash was Quartz, Mullite, Sillimanite, and Aluminum Phosphate. The scattering electron method was used to determine the particle sizes of fly ash and expansive soil. $1 \%$ sodium chloride by weight/volume was taken in aqueous solution for low calcium content in fly ash, and $5 \%$ of lithium chloride with methanol was used for fly ash with high calcium content for the analysis. The sample was kept in a beaker and continuous stirring was done to avoid accumulation.

\section{Conclusions}

The different tests performed on fly ash and expansive soil explains the behavior of soil for the different compositions used for testing. Some important conclusions which the author has emphasized are given below. Fly ash can decrease the maximum dry density of soil and increase the optimum moisture content, as fly ash has a property of absorbing water, resulting in decreased strength. From the study, if we consider $80 \% \mathrm{FA}$ and $20 \%$ of BCS, then OMC would be $22.5 \%$ and MDD would decrease to 1.34 $\mathrm{gm} / \mathrm{cc}$, as compared to other compositions. Expansive soil can only be stabilized using 10 to $20 \%$ of fly ash; increasing the content of fly ash will decrease the properties of soil. X-Ray diffraction and scanning electron microscopy method are useful in determining the chemical composition, mineralogy, and particle shape of black cotton soil and fly ash. The particle size distribution curve helps to determine the gradation of material, and here, we can say the soil is well-graded soil, so further analysis is done based on its PSD curve, in which we obtain that $99.85 \%$ of particles are finer than $2.36 \mathrm{~mm}$. Standard proctor test was performed using various different soils, sand, and fly ash composition to calculate its strength at different water content and to determine the optimum moisture at which the sample gives maximum density. Such results were used for the analysis. For average proportions, if we consider $40 \% \mathrm{FA}$ and $60 \% \mathrm{BCS}$, the $\mathrm{OMC}$ is $15.56 \%$, and MDD will be $1.62 \mathrm{gm} / \mathrm{cc}$, forming the above result calculated. This study definitely helps researchers who are studying the behavior of expansive soil with the addition of fly ash. 


\section{Acknowledgements}

The author would like to thank all the teaching and lab attendants for their help throughout the research at the National Institute of Technology, Raipur; also, the author wants to thank all the reviewers for their valuable comments which helped in making this research more impactful and effective.

\section{References}

[1] F Zha, S Liu, YJ Du and K Cui. Behavior of expansive soils stabilized with fly ash. Nat. Hazards 2008; 47, 509-23.

[2] R Gobinath, GP Ganapathy, II Akinwumi, S Kovendiran, S Hema and M Thangaraj. Plasticity, strength, permeability and compressibility characteristics of black cotton soil stabilized with precipitated silica. J. Cent. S. Univ. 2016; 23, 2688-94.

[3] CC Ikeagwuani and DC Nwonu. Emerging trends in expansive soil stabilisation: A review. J. Rock Mech. Geotech. Eng. 2019; 11, 423-40.

[4] PV Sivapullaiah, JP Prashanth and A Sridharan, Effect of fly ash on the index properties of black cotton soil. Soils Found. 1996; 36, 97-103.

[5] SR Kaniraj and V Gayathri. Permeability and consolidation characteristics of compacted fly ash. $J$. Energ. Eng. 2004; 130, 18-43.

[6] S Khan, J Ivoke and M Nobahar. Coupled effect of wet-dry cycles and rainfall on highway slope made of Yazoo clay. Geosciences 2019; 9, 341.

[7] F Khan, TK Rao and HD Bhave. Classification of foundation soil: Using Geoinformatics (GIS). Int. J. Civ. Eng. Tech. 2018; 9, 1199-207.

[8] A Jain, AK Choudhary and JN Jha. Influence of rice husk ash on the swelling and strength characteristics of expansive soil. Geotech. Geol. Eng. 2019; 38, 2293-302.

[9] SK Das and Yudhbir. Geotechnical characterization of some Indian fly ashes. J. Mater. Civ. Eng. 2005; 17, 544-52.

[10] LC Dang, B Fatahi and H Khabbaz. Behaviour of expansive soils stabilized with hydrated lime and bagasse fibres. Procedia Eng. 2016; 143, 658-65.

[11] F Khan, B Das, SRK Mishra and M Awasthy. A review on the feasibility and application of geospatial techniques in geotechnical engineering field. Mater. Today Proc. 2021, https://doi.org/10.1016/j.matpr.2021.02.108

[12] M Vail, C Zhu, CS Tang, L Anderson, M Moroski and MT Montalbo-Lomboy. Desiccation cracking behavior of MICP-treated bentonite. Geosciences 2019; 9, 385.

[13] N Tiwari and N Satyam. Experimental study on the influence of polypropylene fiber on the swelling pressure expansion attributes of silica fume stabilized clayey soil. Geosciences 2019; 9, 377.

[14] BRP Kumar and RS Sharma. Effect of fly ash on engineering properties of expansive soils. $J$. Geotech. Geoenviron. Eng. 2004; 130, 764-7.

[15] A Tejasvi and S Kumar. Impact of fly ash on soil properties. Natl. Acad. Sci. Lett. 2012; 35, 13-6.

[16] CS Reddy, S Mohanty and R Shaik. Physical, chemical and geotechnical characterization of fly ash, bottom ash and municipal solid waste from Telangana State in India. Int. J. Geo Eng. 2018; 9, 23.

[17] BA Mir and A Sridharan. Physical and compaction behaviour of clay soil - fly ash mixtures. Geotech. Geol. Eng. 2013; 31, 1059-72.

[18] PS Parhi, L Garanayak, M Mahamaya and SK Das. Stabilization of an expansive soil using alkali activated fly ash based geopolymer. In: L Hoyos and J McCartney (Eds.). Advances in characterization and analysis of expansive soils and rocks. GeoMEast 2017. Sustainable Civil Infrastructures, Springer, Cham, 2018, p. 36-50.

[19] AL Murmu, N Dhole and A Patel. Stabilisation of black cotton soil for subgrade application using fly ash geopolymer. Road Mater. Pavement Des. 2018; 21, 867-85.

[20] S Mahvash, S Lopez-Querol and A Bahadori-Jahromi. Effect of class F fly ash on fine sand compaction through soil stabilization. Heliyon 2017; 3, e00274. 
http://wjst.wu.ac.th

[21] Z Nalbantoğlu. Effectiveness of class C fly ash as an expansive soil stabilizer. Construct. Build. Mater. 2004; 18, 377-81.

[22] AL Murmu, A Jain and A Patel. Mechanical properties of alkali activated fly ash geopolymer stabilized expansive clay. KSCE J. Civ. Eng. 2019; 23, 3875-88.

[23] AL Murmu, and A Patel. Studies on the properties of fly ash-rice husk ash-based geopolymer for use in black cotton soils. Int. J. Geosynthetics Ground Eng. 2020; 6, 38. 